\title{
GPPS-TC-2019-0059
}

\section{NUMERICAL AND EXPERIMENTAL INVESTIGATION OF RIM CAVITY SEALING PERFORMANCE IN A TURBINE STATOR WELL}

\author{
Reyhaneh Banihabib \\ MAPNA Turbine Engineering \& Manufacturing \\ Co. (TUGA) \\ Email: Banihabib.Reyhaneh@mapnaturbine.com \\ Fardis Road, Karaj, Iran
}

\author{
Amir Poursamad \\ MAPNA Turbine Engineering \& Manufacturing \\ Co. (TUGA) \\ Email: Poursamad.Amir@mapnaturbine.com \\ Fardis Road, Karaj, Iran
}

\begin{abstract}
One of the most important tasks of gas turbine secondary air system is to seal stator-rotor cavities in order to prevent hot gas ingestion into disk spaces. Minimizing this sealing flow by an effective rim sealing design reduces secondary air consumption and contributes to machine efficiency and power. Understanding the flow behavior in rim seal area, in interaction with main flow, is vital for improving the design.

In this paper, numerical and experimental investigation of rim cavity sealing performance in a turbine stator well in MAPNA heavy-duty gas turbine MGT-70 is presented. Numerical investigations are performed using 1D models and 3D CFD simulations. Using an in-house flow network simulation tool, a 1D model of the secondary air system is set up. This lumped model is used for simulating the overall flow behavior and distribution. Details of the flow are investigated using high fidelity 3D CFD. Rim cavity sealing path, together with mainstream flow, including upstream and downstream vanes and blades, are modeled considering all geometrical details. The interaction of main and secondary flows in rim area is processed and an approach is proposed to evaluate the sealing effectiveness using CFD simulations.

Furthermore, some tests are conducted in one of MGT70 upgraded units. Pressure and temperature sensors are installed in secondary air system and main flow path, with particular attention to rim cavity area. The test results are adequately utilized to experimentally investigate the overall rim cavity sealing performance, monitor hot gas ingestion, and also validate and tune the numerical simulations.
\end{abstract}

\section{INTRODUCTION}

The main role of secondary air system (SAS) in a gas turbine is to provide sufficient flows for turbine cooling and sealing requirements. One of the most critical zones to be sealed by SAS is the unavoidable gaps between rotor and stator rows in turbine section. Insufficient sealing flow in stator-rotor cavities results in hot gas ingestion into disc spaces and may impose penalties on component life. On the other hand, consuming a high amount of secondary flow for sealing reduces the machine efficiency and power. An efficient rim cavity sealing design is therefore an important issue for turbine performance and life.

The most important questions raised in rim seal design are the followings (Sangan et al. 2013):

- For a given rim seal geometry, how much sealing air is required to ensure a sufficient sealing?

- In the event of ingestion, how much hot gas penetrates to the wheel-space?

- How does the ingested hot gas affect the temperatures in the inner components?

Many studies have been conducted in order to understand the flow behavior near rim seals. The most important objective of the studies is to find the sufficient amount of sealing flow for different configurations and conditions. The extensive researches started back in 1980s when Phadke and Owen tested several seal configurations in different conditions. The ingestion was tracked by pressure measurements and a correlation was used to model the minimum sufficient flow (Phadke and Owen, 1983a). Same authors later presented a formulation for calculating the minimum sufficient flow in externally induced (EI) ingestions (Phadke and Owen, 1983b).

Over the years, different methods have been investigated to better understand and evaluate the hot gas ingestion to stator-rotor gaps. Reichert and Lieser used temperature measurement as an indicator for ingestion (Reichert and Lieser, 1999). Palafox et al. used gas concentration measuring tools to investigate the sealing performance (Palafox et al., 2013). Many rim cavity test rigs have been built to investigate the ingestion phenomena in different rim seal configurations and flow conditions. Most of them are equipped with pressure, temperature and also gas concentration measurements to evaluate the sealing performance by different methods (Coren et al. 2010, Mirzamoghadam et al. 2017, Clark et al. 2017 and Scobie et al. 2017). 
Using computational fluid dynamics (CFD) for simulating flow behavior in rim cavity/main stream zones started with relatively simple models (Hills et al. 1997) and was improved over the years. Mirzamoghadam et al. implemented the interface of stator and rotor domains in both upstream and downstream of cavity to investigate the impact of mixing plane location for simulations with sector models (Mirzamoghadam et al., 2008). In other researches, the instability of hot gas ingestion behavior by full 360-degree models was studied (Wang et al. 2014 and Mirzamoghadam et al. 2017). A comparison between different simulation approaches and experimental measurements was performed by Jakoby et al. (Jakoby et al. 2004).

In this paper, numerical and experimental investigations on rim cavity sealing of turbine stator well performed during upgrade of MAPNA heavy-duty gas turbine MGT-70 are described. A 1D model of the SAS network for the baseline machine is set up and used iteratively during flow path optimization to insure that enough sealing flow is purged and stator-rotor cavities are adequately protected from hot gas ingestion. In order to improve the quality of 1D network in rim cavity areas, some 3D CFD simulations are also performed. The results of these simulations are utilized to tune the 1D model and correlations used for calculating the minimum required sealing flow. A new approach is also proposed for evaluating the sealing effectiveness from CFD simulation results. The results of machine tests, performed on the first unit of the upgraded machine are analyzed and compared to simulation results.

\section{RIM CAVITY SEALING ASSESSMENT IN MGT-70 UPGRADE}

MAPNA gas turbine MGT-70 is a $50-\mathrm{Hz}$ heavy-duty gas turbine which is utilized for power generation in simple and combined cycle. It has a 16-stage axial flow compressor, with a row of variable Inlet Guide Vane (IGV) featuring a fast acting option for grid frequency control. The combustion system consists of two external silo-type combustors, each of which having 8 hybrid burners suitable for operation with gaseous or liquid fuels. The turbine section includes 4 stages (8 rows) of conventionally cast vanes and blades. The first 5 rows, i.e. vanes and blades of the first and the second stages and vane of the third stage, are convectively cooled.

MGT-70(3) is the latest upgrade of this machine in which extensive modifications are applied to compressor and turbine sections compared to the baseline MGT-70 (Poursamad et al. 2019). The compressor section upgrade involves redesign of the first 4 stages while in turbine section, all vanes and blades were redesigned.

The upgrade in MGT-70(3) has been conducted considering retrofit as a constraint; i.e. only those parts are modified that can be replaced in a standard overhaul. Due to the existence of this constraint, the SAS routes are not subject to major modifications in the upgrade and only minor changes can be applied to some elements that can be reached during standard overhaul. However, it is necessary to check the performance of SAS during aerodynamic optimization and cooling system redesign of turbine and compressor vanes and blades to insure the efficient delivery of enough cooling and sealing flows.

The redesign process in compressor and turbine sections modifies the compression and expansion lines respectively. This means that flow pressure and temperature at extraction and injection points in each SAS route is being changed. These modifications in the pressure of SAS extraction and injection points could either increase or decrease the amount of sealing flow and affect rim cavity sealing performance, depending on how the pressure ratio between the extraction and injection point in a specific SAS route is changed.

Hot gas ingestion into stator-rotor cavities is also influenced by circumferential distribution of pressure near the hub of turbine section vanes and blades. In the upgrade process, aerodynamic redesign of turbine vanes and blades airfoils changes the hot gas flow field and results in a new pressure distribution near the hub. Therefore, the performance of rim cavity sealing may be affected by aerodynamic redesign of turbine vanes and blades.

Considering the above mentioned facts, it has been vital to assess rim cavity sealing performance of SAS in the upgrade process to insure that the minimum required sealing flow is still supplied to all stator-rotor cavities and hot gas ingestion into wheel spaces is prevented. Here, such analyses are performed using a combination of three different approaches.

Reduced-order models are used during design iterations. Such models include 1D network model of SAS routes and correlations for determining the minimum required sealing flow to prevent hot gas ingestion. Such models are very fast and therefore, appropriate for design iterations. However, the accuracy of such models and correlations are limited and they should be tuned for the specific geometry and flow conditions of the machine.

High-fidelity 3D CFD simulations are also performed taking into account all geometric details and the interaction between rim cavity and main flow. These simulations contain rim cavity sealing path, together with mainstream flow, including upstream vanes and downstream blades. Such simulations are computationally expensive and timeconsuming and may not be effective during design iterations. They are utilized to investigate the details of the flow in rim cavity area and to tune the correlations and 1D model. A new approach is proposed to define the sealing effectiveness based on the results of CFD simulations.

Finally, experimental measurements are conducted on the first unit of the upgraded machine. These tests include measurement of pressure and temperature in rim cavity area and hot gas path. The results of these measurements are used for online monitoring of hot gas ingestion into stator-rotor cavities. They are also utilized for design validation and tuning the models.

\section{MGT-70 TURBINE STATOR WELL CONFIGURATION}

Turbine stator well of the second stage in MGT-70 gas turbine is selected as an example for this work. A schematic of rim cavity sealing configuration in this stator well is shown in Fig. 1. This configuration is the typical 
configuration that is applied to stator wells in other stages as well.

The sealing flow for stage 2 wheel space is supplied from two sources; the dominant part comes through vane 2 cooling cavity and the smaller fraction comes from blade 2 root cooling flow. The cooling system of vane 2 is designed so that the sealing flow passing through the cavity does not experience a large temperature rise. The sealing flow coming from all vanes are fed to an annular cavity inside the seal ring and are injected to the forward stator-rotor cavity through a number of holes uniformly distributed around the circumference. The flow is mixed with blade root cooling flow and a portion of it seals the forward cavity. The other portion of the flow passes through a labyrinth seal and seals the aft cavity.

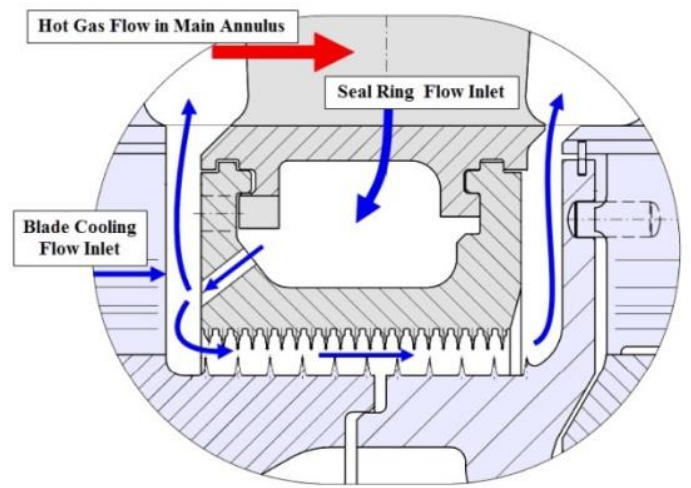

\section{Figure 1 Stage 2 stator well in MGT-70 gas turbine}

The sealing flow for stage 2 wheel space is supplied from two sources; the dominant part comes through vane 2 cooling cavity and the smaller fraction comes from blade 2 root cooling flow. The cooling system of vane 2 is designed so that the sealing flow passing through the cavity does not experience a large temperature rise. The sealing flow coming from all vanes are fed to an annular cavity inside the seal ring and are injected to the forward stator-rotor cavity through a number of holes uniformly distributed around the circumference. The flow is mixed with blade root cooling flow and a portion of it seals the forward cavity. The other portion of the flow passes through a labyrinth seal and seals the aft cavity.

CFD simulation results for compressor and turbine reveals that for SAS route to stage 2 stator well, source to sink pressure ratios are decreased in MGT-70(3) compared to the baseline MGT-70 (Table 1). The source pressure is extracted from compressor multi-stage simulation and sink pressures obtained from turbine multi-stage simulation.

Since these pressure ratios are the main driver for sealing flows, a reduction in their values reduces the sealing flows and increase the probability of hot gas ingestion.

Table 1 Comparison of source to sink pressure ratio for sealing gaps in MGT-70 and MGT-70 (3)

\begin{tabular}{lcc}
\hline & Forward cavity & Aft cavity \\
\hline MGT-70 & 2.03 & 3.02 \\
MGT-70 (3) & 1.68 & 2.57 \\
\hline
\end{tabular}

\section{RIM CAVITY SEALING EFFECTIVENESS}

Sealing effectiveness in a rotor-stator gap is theoretically defined by the ratio of sealing mass flow to egressing mass flow (Sangan et al. 2013):

$$
\varepsilon=\frac{\dot{m}_{o}}{\dot{m}_{e}}=\frac{\dot{m}_{o}}{\dot{m}_{i}+\dot{m}_{o}}=1-\left(\frac{\dot{m}_{i}}{\dot{m}_{e}}\right)
$$

where the subscripts $\mathrm{e}, \mathrm{i}$ and o denote egress, ingress and sealing flows respectively. In order to calculate the sealing effectiveness using CFD simulation results, the amount of ingress and egress mass flow rates passing through the interface between rim cavity and main flow can be simply calculated by considering the flow direction and sealing effectiveness is then calculated by Eq. 1. Since this model concerns about mass flow passing through a surface in the interface, the above-mentioned effectiveness is referred to as "surface effectiveness" here.

There are two problems with this approach. First, flow structures in cavity/main flow interface cause the sealing flow re-ingest to the cavity or re-ingest to downstream cavities. This kind of ingress is not unfavourable and should not decrease the value of effectiveness. However, the above approach gives a lower effectiveness in the event of such reingestions. Second, this approach does not take into account the depth to which the ingested hot gas penetrates to the cavity. In a real machine, hot gas ingesting into the statorrotor cavities down to a certain level is tolerated. In fact, designing a rim sealing with zero ingestion requires a large amount of sealing flow, which reduces the machine efficiency.

Considering above-mentioned points, it seems that the sealing effectiveness must capture the amount and penetration depth of "hot gas" ingested to the cavity. Using CFD simulations, it is easy to define the effectiveness to consider both factors. If a control volume is defined near the ingestion area in rim cavity, the fraction of hot gas to the whole control volume mass shows the amount of hot gas present in rim cavity. This kind of effectiveness, referred to as "volume effectiveness" here, only concerns about the amount of hot gas occupying the rim cavity, which plays the main role in wall temperature rise in wheel space. The definition of volume effectiveness is:

$$
\eta=1-\frac{m_{H G \text { in } C V}}{m_{C V}}=\frac{m_{C A \text { in } C V}}{m_{C V}}=\frac{\iiint_{C V} c \rho d v}{m_{C V}}
$$

As an example, consider the three ingestion patterns shown in Fig. 2. Two control volumes are considered which cover the whole rim cavity together. The first control volume (CV1) starts from cavity/main flow interface and comes down to a radius where partial ingestion of hot gas is tolerable to a certain degree. Then, there is the second control volume (CV2) starting just after CV1 down to the bottom of rim cavity.

All cases are assumed to have equal sealing and ingress mass flow rates. The ingested gas may be a combination of hot gas and cooling air (a re-ingestion case for instance) and contains equal amount of hot gas. The ingestion depth, on the other hand, is different for each case. 


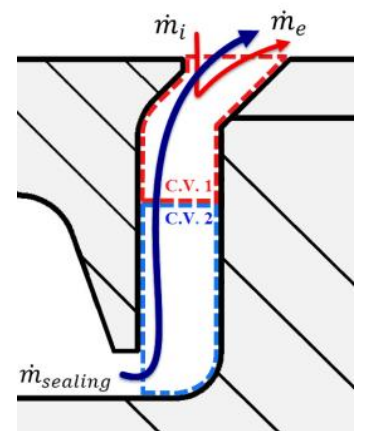

(a)

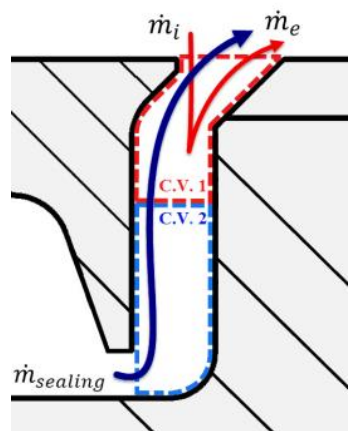

(b)

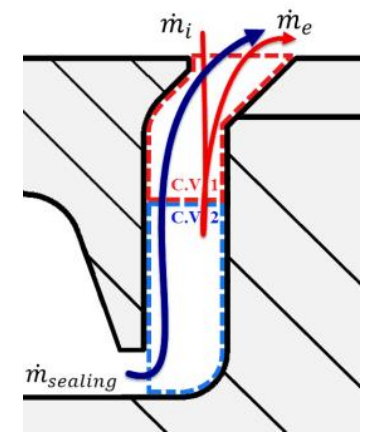

(c)

Figure 2 Possible ingestion patterns, (a) \& (b) ingested flow is limited to CV1, (c) ingested flow reaches to CV2

For surface effectiveness, the amount of egress flow is:

$$
\dot{m}_{e}=\dot{m}_{i}+\dot{m}_{0}
$$

which is identical for all cases and therefore, surface effectiveness would be equal for all these cases:

$$
\varepsilon_{1}=\varepsilon_{2}=\varepsilon_{3}
$$

First, this value underestimate the effectiveness as it does not differentiate between hot gas and coolant in the ingested flow.

Second, Eq. (4) shows that surface effectiveness is not sensitive to ingestion depth and it is equal for all three patterns. On the other hand, calculation of volume effectiveness for CV1 gives:

and for CV2 results:

$$
\eta_{1}>\eta_{2}>\eta_{3}
$$

$$
\eta_{1}=\eta_{2}>\eta_{3}
$$

The CV2 volume effectiveness is $100 \%$ for the first and second ingestion patterns and is less for the third one.

The volume effectiveness definition considers only the hot gas ingestion as destructive effect to sealing performance and in the event of re-ingestion; the values of volume effectiveness will be higher than surface effectiveness for the same case.

It is also important to consider the relation between numerical and experimental approaches for sealing performance assessments. There are two well-known approaches usually adopted in rim cavity sealing experiments.

One approach is based on temperature measurements in which, hot gas with temperature, $\mathrm{T}_{\mathrm{HG}}$, ingresses into wheel space which is supplied with secondary air with temperature $\mathrm{T}_{\mathrm{CA}}$. The mixture of hot gas and secondary air results temperature $\mathrm{T}$ in wheel space. Sealing effectiveness is then defined as (Reichert and Lieser 1999):

$$
\eta_{\mathrm{T}}=\frac{\mathrm{T}_{\mathrm{HG}}-\mathrm{T}}{\mathrm{T}_{\mathrm{HG}}-\mathrm{T}_{\mathrm{CA}}}
$$

This method is compliant with purpose of sealing, i.e. to protect internal components from high temperature ingestions. The closer the cavity temperature is to the SAS flow temperature, higher sealing effectiveness will be obtained. However, it should be noted that ingestion is not the only parameter causing cavity flow temperature rise and other effects, such as heat transfer from cavity wall and windage could influence the cavity temperature too. It means that by using temperature instead of mass fraction in the definition of volume effectiveness, it would result different sealing effectiveness for two similar cavities with different wall temperatures.

Other method uses gas concentration measurements, where the cooling flow is fed with a known concentration of a certain gas (e.g. CO2). The test section is equipped with a series of gas sampling tubes, installed on one or more radial locations on stator wall. These sampling tubes extracts a little amount of cavity flow and a gas composition analyzer shows the concentration of extracted gas. The concentration is an indicator of hot gas/cooling air mixture that shows the amount hot gas ingestion into the rim cavity and effectiveness is defines as (Sangan et al. 2013):

$$
\eta_{c}=\frac{c-c_{H G}}{c_{C A}-c_{H G}}
$$

The volume effectiveness is more consistent with this approach, because only hot gas ingestion affects concentration and penetration depth is also considered by installing the instruments in different radial positions. It should be noted that there might be a difference between experimentally calculated effectiveness and the volume effectiveness calculated from numerical simulations; because, in experiments, the concentration sampling tubes are usually installed on stator walls and will not capture the concentration in the whole cavity volume. The volume effectiveness is an ideal definition that can be used in numerical simulations.

\section{D CFD SIMULATION OF FLOW IN TURBINE STATOR WELL}

For 3D CFD simulation of flow in MGT-70 second stage stator well shown in Fig. 1, the simulation domain includes rim cavity sealing path and hot gas flow path. The hot gas flow path includes blade 1 , vane 2 and blade 2 to capture the influence of upstream and downstream blades and vanes on both forward and aft cavities. The rim cavity sealing path starts from flow leaving the vane internal cavity, seal ring cavity followed by seal ring holes, labyrinth seal and both forward and aft cavities.

Mixing plane is chosen for modelling the interface between stationary and rotating domains. Nevertheless, in order to examine the effect of vane/blade interface and 
clocking position, some simulations were also performed with different interfaces and adjusted vane/blade count. Results of these calculations showed no significant variations from mixing plane approach. Figure 3 shows the simulation domain with the inlet and outlet boundaries for main flow and rotor-stator interfaces.

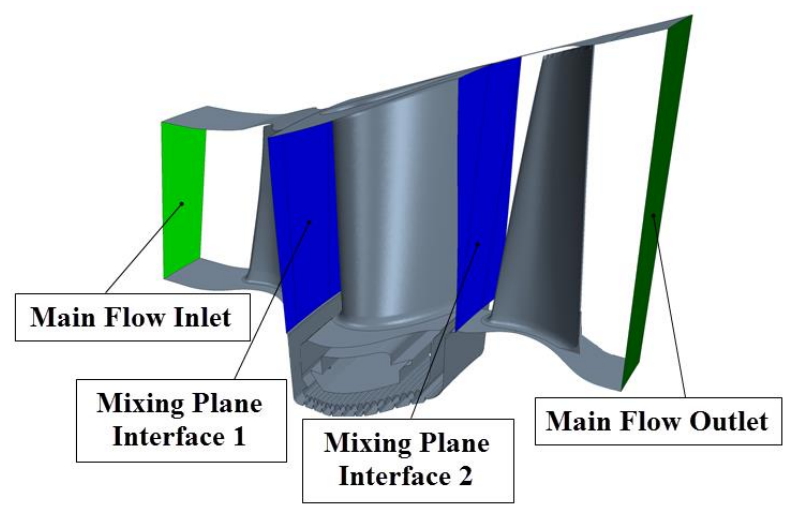

\section{Figure 3 Simulation domain and main flow} boundaries

Moreover, the cooling and sealing flow inlets to the domain include seal ring flow from vane 2 cavity and the flow coming from blade 1 root. The cooling flows from vane and blade tips and trailing edges are also considered. All SAS inlet locations are described in Fig. 4.

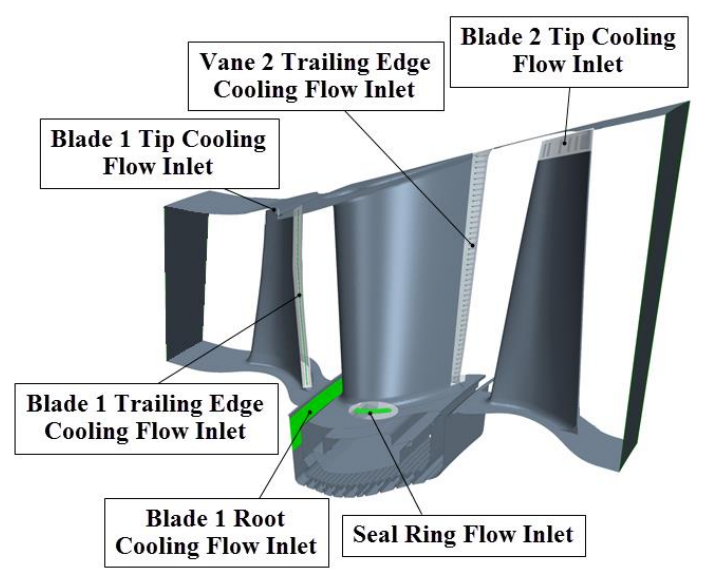

\section{Figure 4 Simulation domain and SAS flow boundaries}

The mesh contains a total of 23.5 million cells. The baseline simulation was initially performed with coarse mesh settings and refinements were applied while monitoring the ingestion flow parameters in both cavities. When these flow parameters did not show significant changes with mesh, the mesh settings were chosen as reference mesh setup. The wall $\mathrm{Y}+$ values for cavity flow path, shown in Fig. 5 are below 4 which indicate a sufficient refinement near the wall surfaces for turbulence model used in simulations.

Calculations are performed as steady state 3D RANS, using SST k-omega for turbulence model. In order to be able to track sealing air/hot gas interactions, a multi-component approach was implemented where two gasses with different chemical compositions were assigned to sealing flow and to main flow, named cooling air (CA) and combustion gas respectively. An indicator was defined based on concentration of $\mathrm{CA}$, which shows the mass fraction of $\mathrm{CA}$ to total air occupying a certain volume.

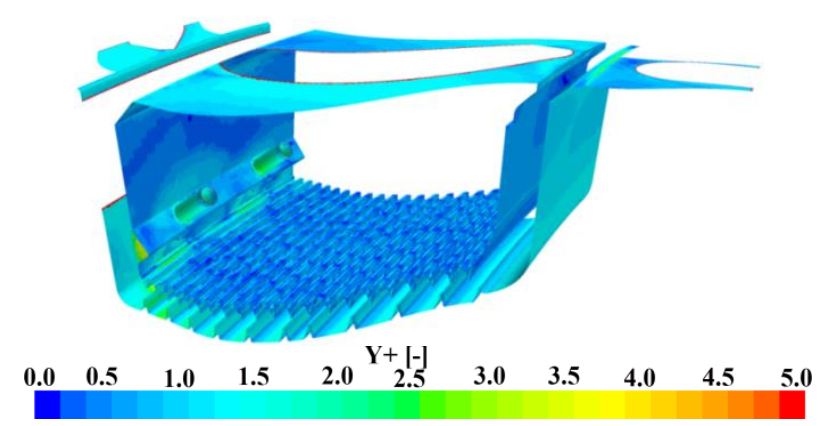

Figure $\mathbf{5}$ Wall $\mathrm{Y}+$ for stator well cavity wall

The main flow boundary conditions were extracted from a multi-stage aerodynamic 3D CFD simulation of the whole turbine section. The sealing flow coming from vane cavity and other coolant flows, such as the vane and blade tips and trailing edges, are obtained from 3D conjugate heat transfer (CHT) simulation of each row. The inlet from blade root cooling is calculated from a 1D SAS network simulation. The running clearances and wall temperatures are obtained from a finite element thermo-mechanical simulation of the whole machine.

In order to investigate the flow condition in cavity/main flow interface, both flow direction and CA concentration were reported on this surface. The result is shown in Fig. 6. The contour shows the intensity of cooling air in both ingress and egress zones, and ingress/egress border is shown with black narrow line.

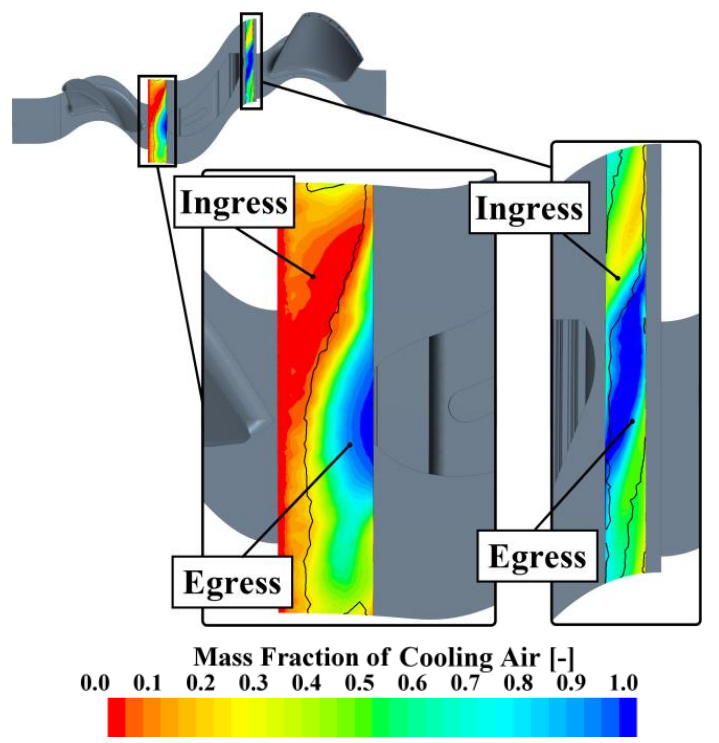

\section{Figure 6 Mass fraction of cooling air on cavity/main flow interface}

As it is observed, in forward cavity the ingress takes place mostly near the rotating wall while in aft cavity the dominant part of ingestion occurs near the stationary wall. This is because of dominant effect of main flow pressure field on ingestion, i.e. the externally induced (EI) ingestion. For the forward cavity, moving from upstream blade to downstream vane, main flow pressure decreases and 
circumferential gradient of pressure increases. As a result, ingress is mainly observed near the blade, while egress is seen close to vane, gradually changing to ingestion in circumferential direction.

It is interesting to note that cooling air fraction in ingesting flow is not zero in neither of cavities showing that the ingress is not pure hot gas ingestion. In aft cavity, the cooling air fraction in ingestion is higher which is due to reingestion from forward cavity.

Two circumferential sections containing cooling air ingestion are selected and shown in Fig. 7 and Fig. 8. These views perfectly clarify the above explanations. In vector view, the color represents the cooling air concentration and vector size shows the magnitude of velocity.

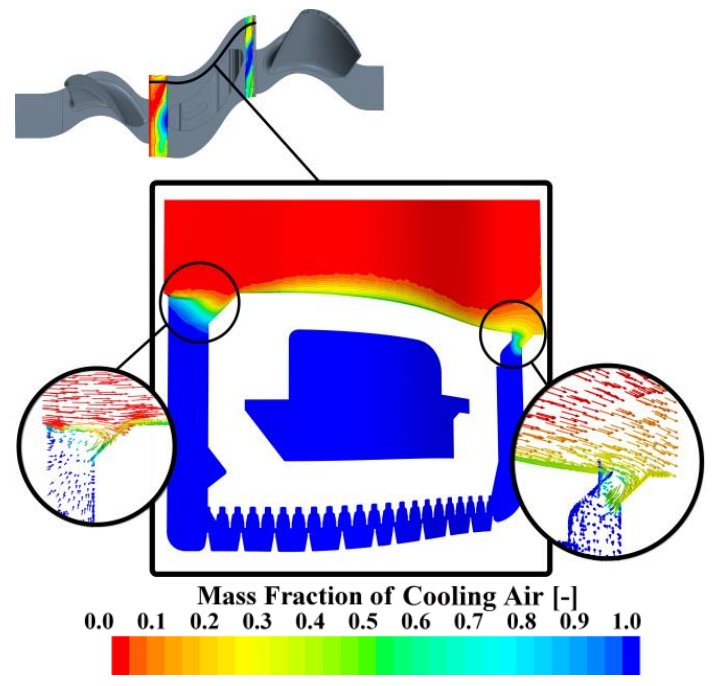

Figure 7 Meridian section at $10 \%$ of sector, viewing cooling air concentration

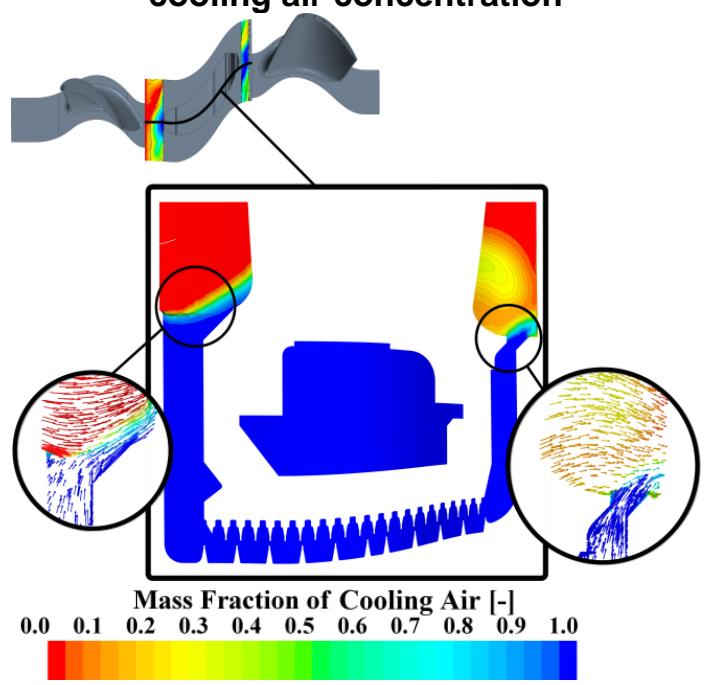

Figure 8 Meridian section at $50 \%$ of sector, viewing cooling air concentration

As previously explained, the cooling air in stator well is supplied from two sources. In order to realize the share of each source in each cavity, the streamlines are presented in Fig. 9 with different color for the two sources. The figure shows that all blade root coolant tends to flow through forward cavity. The flow coming from seal holes, on the other hand, is divided unevenly between the two cavities, with the greater portion through forward cavity.

Two control volumes are defined for calculation of effectiveness in each cavity as shown in Fig. 10. The upper control volume (CV1) starts from cavity/main flow interface down to a radius to which, partial hot gas ingestion is tolerated. The effectiveness is calculated based on this volume. The lower one (CV2) starts just after CV1 and no ingestion is allowed to this volume, i.e. the effectiveness must be $100 \%$ for this volume. A control surface is also defined in the interface between control volumes and temperature is observed in this section as another indicator of ingestion. Sealing effectiveness for both forward and aft cavity is calculated using both surface and volume effectiveness definitions. The results are shown in Table 2.

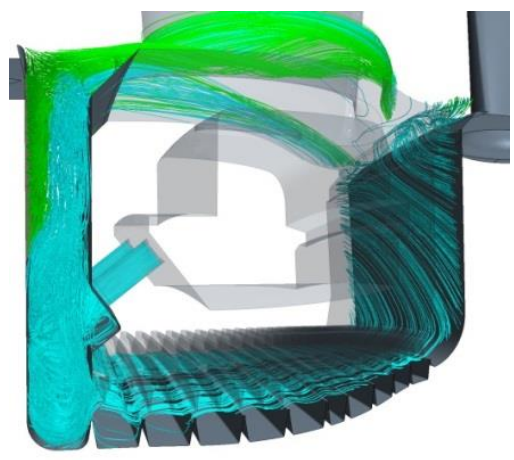

Figure 9 Streamlines for cooling air flow starting from seal ring holes (blue) and B1 root (green)

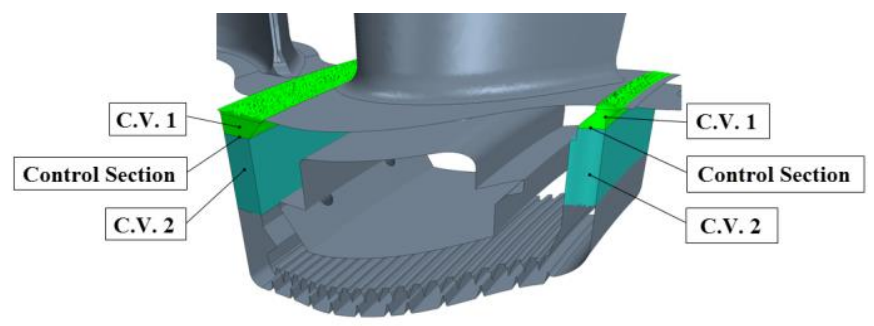

Figure 10 Control volumes and sections defined for evaluation of sealing effectiveness in forward and aft cavities

Table 2 Sealing performance in forward and aft cavities

\begin{tabular}{lccccc}
\hline & $\varepsilon$ & $\eta_{\mathrm{CV} 1}$ & $\eta_{\mathrm{CV} 2}$ & $\max \mathrm{T}_{\text {Walls }}$ & $\mathrm{Tt}_{\text {Control Section }}$ \\
\hline Forward Cavity & 0.84 & 0.77 & 1.00 & 0.67 & 0.68 \\
Aft Cavity & 0.75 & 0.86 & 1.00 & 0.63 & 0.56 \\
\hline
\end{tabular}

A simulation with adiabatic cavity walls has also been conducted in order to extract the adiabatic wall temperatures. Having heat fluxes from the first simulation and adiabatic wall temperature distribution from the second one, the distribution of heat transfer coefficient (HTC) on cavity walls are calculated by Eq. 9:

$$
H T C=\frac{q}{T_{\text {wall }}-T_{\text {adiabatic wall }}}
$$


The extracted heat transfer coefficients are used for tuning the heat transfer correlations implemented in whole engine thermal analyses and 1D simulations of SAS network.

Moreover, the adiabatic wall case could be used for investigating the effect of hot gas ingestion on cavity wall temperature. Contours of normalized temperature on walls of both cavities are brought in Fig.11 and Fig.12. The temperature is normalized as follows:

$$
T_{\text {normalized }}=\frac{T-T_{\min }}{T_{\text {ref }}-T_{\min }}
$$

where $\mathrm{T}_{\text {ref }}$ is the maximum allowable working temperature of wheel space components, which is adequately below the critical temperature. As it is shown in Fig. 11 and Fig. 12, high temperatures are limited to a zone near hub radius which is permissible depth for hot gas ingestion. Underneath that, the normalized temperature value is below 1 which means the temperature is below the allowable value. Maximum normalized wall temperatures for CV2 are shown in the fourth column of Table 2. Moreover, the average value of normalized temperature on control sections (see Fig. 10) are calculated and reported in the last column of Table 2.

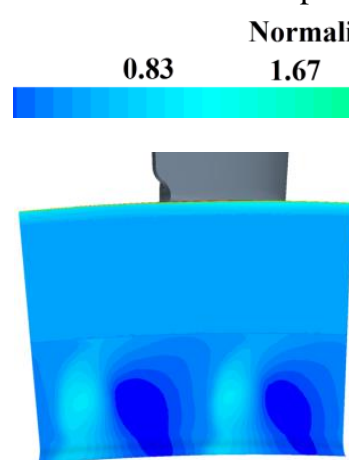

(a)

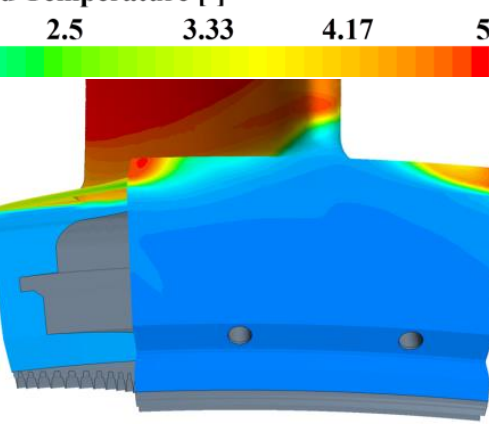

(b)
Figure 11 Contour of normalized temperature on forward cavity wall: (a) rotating wall, (b) stationary wall

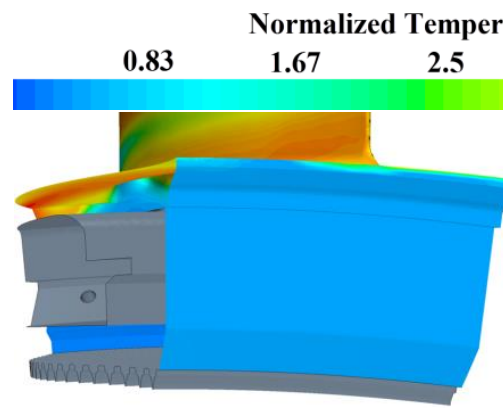

(a)

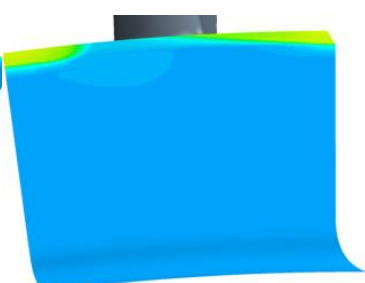

(b)
Figure 12 Contour of normalized temperature on aft cavity wall: (a) stationary wall, (b) rotating wall

Comparing the effectiveness values reported in Table 2, an inconsistency is realized between two definitions. The surface effectiveness $(\varepsilon)$ indicates a better sealing performance in forward cavity rather than aft cavity. However the volume effectiveness $(\eta)$ shows the opposite. Comparing the thermal conditions of both cavities, it is evident that the temperature levels in aft cavity are lower than forward cavity. This is visible from temperature values reported in two last columns of Table 2 and also the contours shown in Fig. 11 and Fig. 12. This means that volume effectiveness is more compliant with thermal condition and is a better performance index for sealing assessments.

It is worth mentioning that the reason behind the inconsistency between two definitions in this case is cooling air re-ingestion form forward cavity into aft cavity which is visible from Fig. 7. As it is expected, the surface effectiveness definition (Eq. (1)) will not capture this phenomenon and therefore, a low value of effectiveness is obtained from this definition.

\section{CORRELATIONS FOR CALCULATION OF MINIMUM REQUIRED RIM CAVITY SEALING FLOW}

Many researches have been conducted in order to formulate the minimum sealing flow required to seal rim cavities. To achieve this goal, advanced test rigs have been constructed and equipped with numerous sensors monitoring both cooling and main flow conditions. In these experiments, the sealing flow fed to rim cavity and sealing effectiveness obtained and the $\varepsilon-\mathrm{C}_{\mathrm{w}}$ diagram are ploted. The lowest value of $\mathrm{C}_{\mathrm{w}}$ resulting the maximum effectiveness is reported as $\mathrm{C}_{\mathrm{w} \text {,min }}$.

The most common formulation for non-dimensional mass flow resulting maximum effectiveness is (Phadke and Owen, 1983):

$$
C_{w, \min }=K .2 \pi \cdot G_{c} \cdot \sqrt{0.5 C_{p, \max }} \cdot R e_{w}
$$

in which $\mathrm{K}$ is an empirical factor which depends on seal geometry and configuration. $\mathrm{G}_{\mathrm{c}}$ is non-dimensional seal gap ratio:

$$
G_{c}=\frac{S}{R}
$$

$\mathrm{C}_{\mathrm{p} \text {,max }}$ is non-dimensional maximum pressure diffrence in main flow at hub defined as:

$$
C_{p, \text { max }}=\frac{p_{\text {hub,max }}-p_{\text {hub,min }}}{0.5 \cdot \rho_{1} \cdot w_{1}^{2}}
$$

where $\rho_{1}$ and $c_{1}$ are density and axial velocity of main flow upstream of rim cavity. The $\mathrm{Re}_{\mathrm{W}}$ in Eq. (11) is the main flow Reynolds number:

$$
R e_{w}=\frac{\rho w R}{\mu}
$$

The formulation of $\mathrm{C}_{\mathrm{w} \text {,min }}$ indicates that minimum required sealing flow depends on seal configuration $(\mathrm{K})$, seal gap $\left(\mathrm{G}_{\mathrm{c}}\right)$ and main stream condition $\left(\sqrt{0.5 C_{p, \max }} \cdot \mathrm{Re}_{\mathrm{w}}\right)$. In other words, the non-dimensional seal flow has a linear dependancy on seal gap ratio and main stream condition. Finding the $\mathrm{K}$ factor is one of the most common objects of rim cavity sealing researches and many exeprimental investigations has been conducted to determine this value.

Reviewing the literature, it is common to see a discrepancy among the reported values for $\mathrm{K}$ for same configurations. One reason is the different evaluations of main flow conditions. First, there is the evaluation of Reynolds number $\left(\mathrm{Re}_{\mathrm{w}}\right)$; while some reserchers use mean axial velocity of main flow (Sangan et al. 2013), the others 
use mean absolute velocity (Bohn and Wolff, 2003). The other source of discrepancy is the location for evaluating the main flow pressure for calculation of $C_{p, \text { max }}$. For a given rim cavity with upstream stationary vane and downstream rotating blade, usually the main flow pressure measurements are performed on vane hub area after vane airfoil. As measurement location changes from the vane trailing edge to rim area, main flow pressure peaks and valleys are damped and the value of $C_{p, \max }$ decreases. Therefore, for the same configuration with the same amount of $\mathrm{C}_{\mathrm{w} \text {,min }}$, different $\mathrm{K}$ factors could be obtained.

In this work, to find $\mathrm{C}_{\mathrm{w} \text {,min }}$ for each rim cavirty, after evaluating the sealing effectiveness for rim cavities in reference conditions, several simulations are performed with different sealing mass flows and the $\varepsilon-C_{w}$ diagram is ploted as shown in Fig.13 and Fig.14.

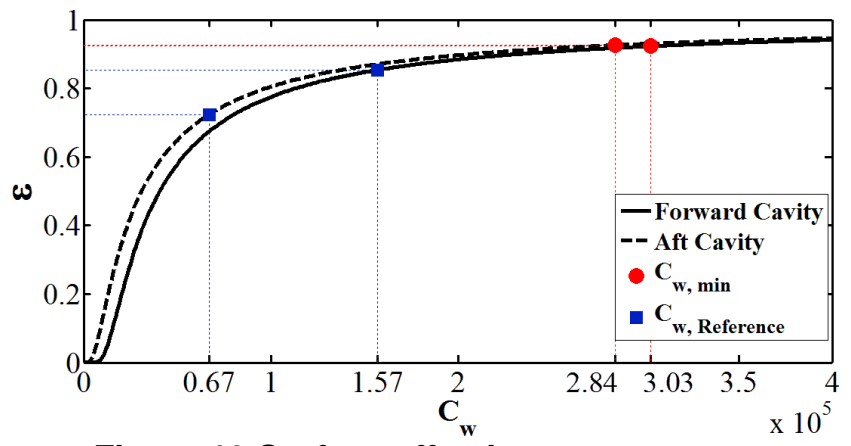

Figure 13 Surface effectiveness vs. nondimensional sealing mass flow

In order to estimate $\mathrm{C}_{\mathrm{w} \text {,min }}$ from these plots, the criterion introduced by Bohn and Wolff (Bohn and Wolff, 2003) is used. The gradient of the sealing effectiveness in dependence of $\mathrm{C}_{\mathrm{w}}$ is evaluated and the values of $\mathrm{C}_{\mathrm{w}, \min }$ is defined:

$$
\frac{\partial \varepsilon}{\partial C_{w}}=\text { Criterion }
$$

In Fig.13, the solid and dashed lines are sealing characteristic curves for forward and aft cavities respectively. The value of $C_{w, m i n}$ is marked with red point and the value of $\mathrm{C}_{\mathrm{w}}$ in the reference case is shown as a blue square. Although the cavities are adequately sealed, the sealing mass flow in the reference case is lower than $\mathrm{C}_{\mathrm{w} \text {,min }}$ value in both cavities as seen Fig. 13 and $C_{w, m i n}$ calculated from this curve is not correct. Based on previous explanations about volume effectiveness, it is expected that volume effectiveness gives better estimation of $C_{w, m i n}$. The diagram of $\eta-C_{w}$ variations is ploted in Fig. 14 and Fig. 15 based on CV1 and CV2, respectively. It is evident that the sealing mass flow is also less than minimum required sealing flow obtained based on CV1. But, the minimum required sealing flow derived based on $\mathrm{CV} 2$ is the right value based on sealing requirements for these cavities and is higher than the sealing flow.

Using the values obtained for $C_{w, m i n}$, the empirical $K$ factor for forward and aft cavities can be calculated. In order to be able to verify the model and compare the results with literature, $\mathrm{K}$ factors calculated using $\mathrm{C}_{\mathrm{w} \text {,min }}$ values based on surface effectiveness are brought here. Values of $\mathrm{K}$ factors are shown in Fig. 16 together with experimental results for some rim cavity sealing configurations reported in literature.

The aft cavity configuration in this study is geometrically between configurations 1 and 2 and the results show that the calculated value for $\mathrm{K}$ also lies between values reported for these two configurations. For the forward cavity, the results are different. Since the geometry of forward cavity is very close to configuration 1 , a high value of $K$, at least higher than the value calculated for forward cavity, was expected. However, the resultant $\mathrm{K}$ factor is very low. This might be attributed to the fact that for this cavity, the blade is located upstream the cavity and vane is downstream. This means that for a specific rim seal configuration, a lower factor for $\mathrm{K}$ factor is expected in rotor-stator cavities compared to stator-rotor cavities.

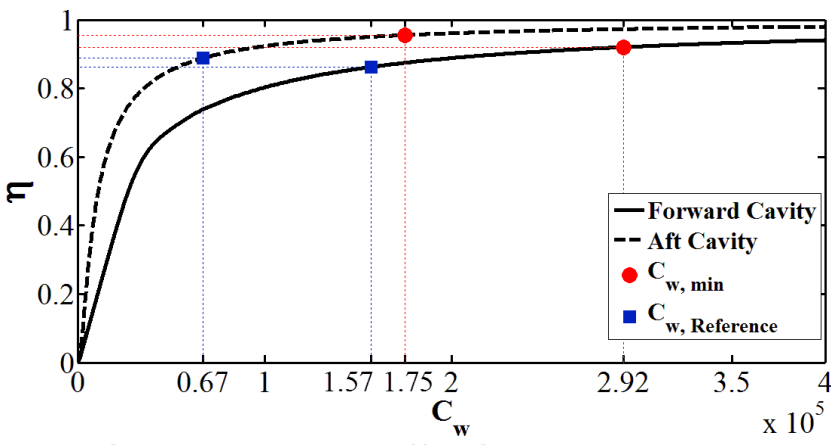

Figure 14 Volume effectiveness vs. nondimensional sealing mass flow - based on CV1

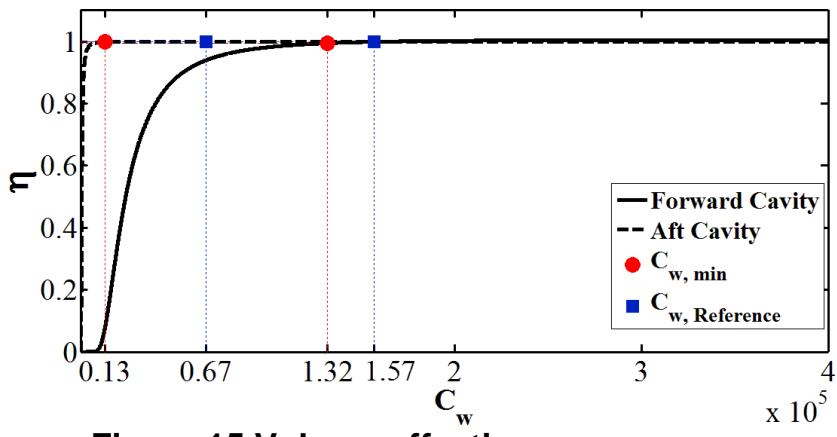

Figure 15 Volume effectiveness vs. nondimensional sealing mass flow - based on CV2

As explained before, the value of $\mathrm{C}_{\mathrm{p} \text {,max }}$ depends on the location where static pressure is read in main stream. Evaluating different locations for mixing plane and different axial locations for pressure reading shows that vane is the main contributor to asymmetries in pressure distribution, whether it is located upstream or downstream the cavity, while blades help to damp the peaks and valleys. The mixing plane interface should be placed before cavity when the blade is upstream, and should be located after cavity where vane is downstream of the cavity. The distribution of normalized static pressure on hub near forward cavity is shown in Fig. 17. 


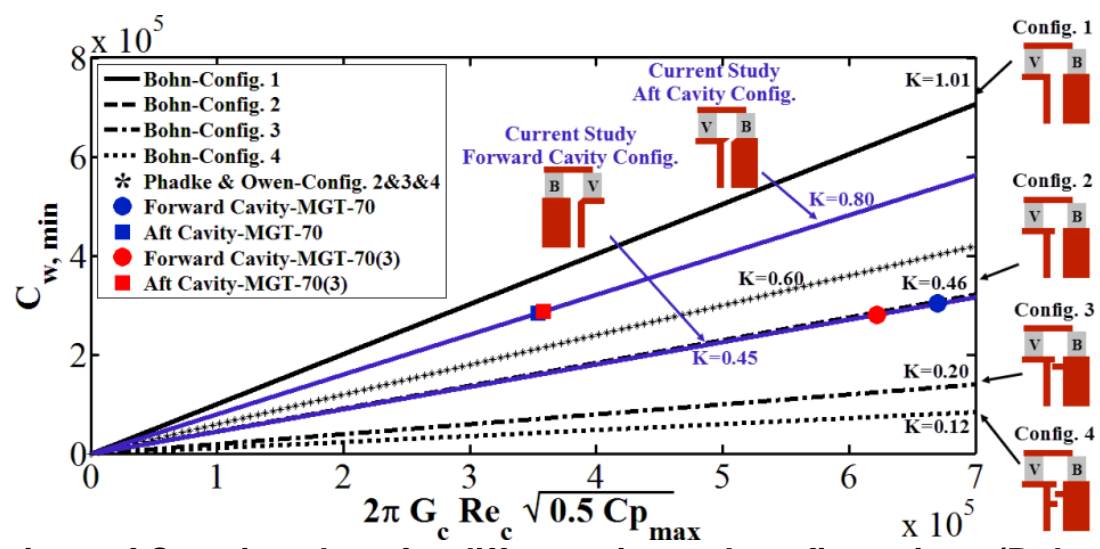

Figure 16 Comparison of $\mathrm{Cw}$,min values for different rim seal configurations (Bohn and Wolff, 2003).

Recalling the discussion about ingress and egress zones in forward and aft cavities (Fig. 6), when the vane is upstream of the cavity, the maximum mean pressure values and maximum $\mathrm{C}_{\mathrm{p} \text {,max }}$ values occure at the same place, near the vane. Whereas, in aft cavity, the mean pressure is higher near the blade, but the maximum $\left(C_{p \text {,max }}\right)$ takes place near the downstream vane. The combined effect of high mean pressure and high $C_{p \text {,max }}$ values near the vanes in aft cavity results higher ingestion values which leads to higher $\mathrm{K}$ values. On the other hand, in forward cavity, high mean pressure and high $\mathrm{C}_{\mathrm{p} \text {,max }}$ occures in separated locations and less ingestion is expeted. Therefore, a lower value of $\mathrm{K}$ is obtained in this seal.

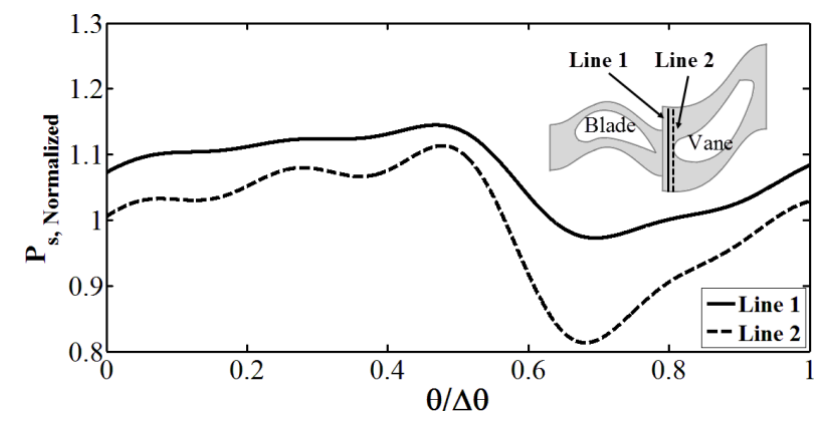
Figure 17 Non-dimensional pressure distribution on
hub near forward cavity

This means that for using Eq. (11), care should be taken both with calculation of main flow properties (velocity for $\mathrm{Re}_{\mathrm{w}}$ and pressure reading location for $\mathrm{C}_{\mathrm{p} \text {,max }}$ ) and also, type of rim cavity (stator-rotor or rotor-stator) will cause a difference in $\mathrm{K}$ factor. For aft cavity it is reasonable to read the pressure distribution upstream of the cavity, while for forward cavity, with upstream blade and downstram vane, the pressure distribution downstream of cavity should be used for calculation of $C_{p, \max }$.

During design iterations in the upgrade of MGT-70, the minimum required sealing flow for rim cavities are predicted using Eq. (11). Since the configuration of rim seals is not modified, $\mathrm{K}$ factor and $\mathrm{G}_{\mathrm{c}}$ value will be the same. Calculating Reynolds number and $\mathrm{C}_{\mathrm{p} \text {,max }}$ from aerodynamic simulations of turbine flowpath, $\mathrm{C}_{\mathrm{w} \text {,min }}$ value is calculated.

Comparing the values for the second stage rim cavities in the baseline and upgraded turbine MGT-70(3), shows that $\mathrm{C}_{\mathrm{w} \text {,min }}$ value is decreased for forward rim cavity in the upgraded turbine while for aft cavity, it is almost the same. In forward cavity, mean pressure level of main stream is increased, but the difference between maximum and minimum pressure is decreased considerably. This leads to a lower $C_{P, \max }$ value in the upgraded turbine. Moreover, the density of main flow is higher in MGT-70(3) turbine due to higher pressure, but the axial velocity is lower compared to MGT-70 turbine and the Reynolds number in the upgraded turbine is slightly lower. Altogether, a smaller value of $2 \pi G_{c} \sqrt{0.5 C_{p, \max }} R_{W}$ is obtained for the upgraded turbine.

\section{D SIMULATION OF FLOW IN TURBINE STATOR WELL}

A 1D network model of the SAS in MGT-70 is also set up in which elements are tuned using CFD simulation results. Different boundary conditions are implemented in both CFD and 1D simulations and elements are modified to better fit to CFD results. This model is combined with the correlations described in previous section to obtain a reliable $1 \mathrm{D}$ network model capable of predicting pressure losses and temperature rises due to windage and wall temperatures.

The schematic view of a portion of $1 \mathrm{D}$ network for the second stage stator well is shown in Fig. 18. Using this 1D simulation, the performance of sealing in stator well cavities is simulated for new upgraded turbine as well. Many 1D simulations are conducted for different off-design conditions. The results showed sufficient sealing with acceptable temperature levels in all cases which ensured that the original seal ring is perfectly applicable for the new machine. The results are compared to measurement results in the next section.

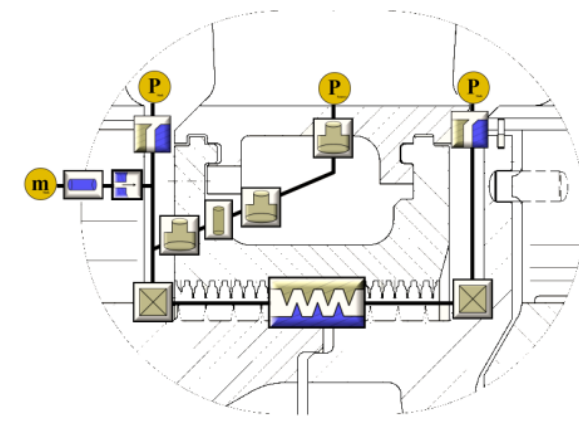

Figure 18 Schematic view of 1D simulation for sealing flow path in stage 2 stator well 


\section{FIELD TESTING AND VALIDATION}

The first upgrade to MGT-70(3) was tested in the spring of 2017 during overhaul of an MGT-70 unit planned to be upgraded in Parand power plant, southwest of Tehran. Many sensors were installed in different locations of main flow and SAS routes. In SAS measurements, special attention was taken to turbine rim sealing performance. For instance, the sealing performance of stage 2 stator well was monitored using 18 sensors; 9 thermocouples and 9 pressure transducers. The measuring points are selected in 3 axial positions: inside the seal ring, inside the forward cavity and inside the aft cavity as shown schematically in Fig. 19. Three vanes in different circumferential positions were instrumented to insure enough redundancy and also capture pitch-wise asymmetries. The installed sensors are shown in Fig. 20.

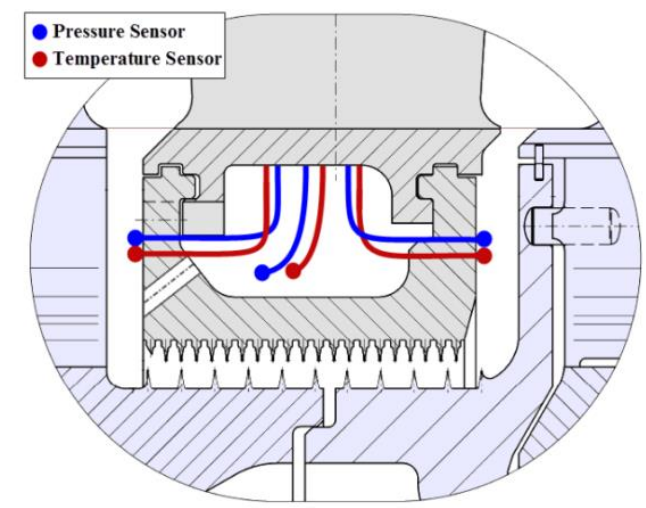

Figure 19 Measuring points in stage 2 seal ring area

Measurement data acquired for different turbine operating conditions show sufficient sealing in all rim cavities. No ingestion is detected since the measured temperatures are considerably below the critical value.

Moreover, the temperature values predicted by $1 \mathrm{D}$ code are compared to test data for different operating modes and shows good compliance. Normalized values of temperature in both forward and aft cavities are shown in Fig. 21. The values for forward cavity are shown with blue marks and aft with red marks. The mark shapes represent the data source.

Collected data from thermocouples laid in $\pm 4 K$ band for forward cavity and $\pm 7 K$ band for aft cavity. Regarding the data distribution and deviations from average value, a $95 \%$ confidence interval of normalized values is a \pm 0.0015 band around reported values which is not shown in Fig. 21.

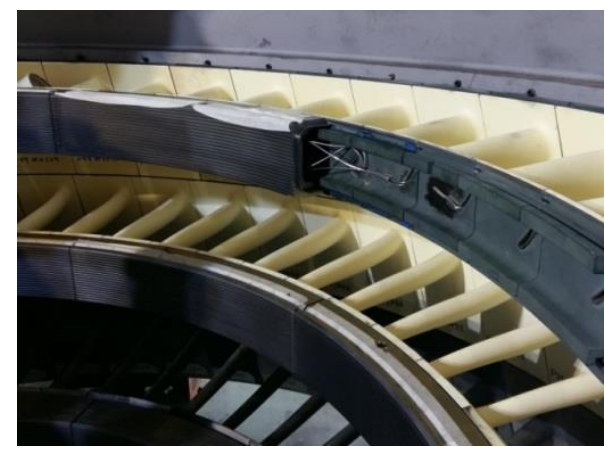

Figure 20 Pressure taps and thermocouples installed on stage 2 seal ring during overhaul

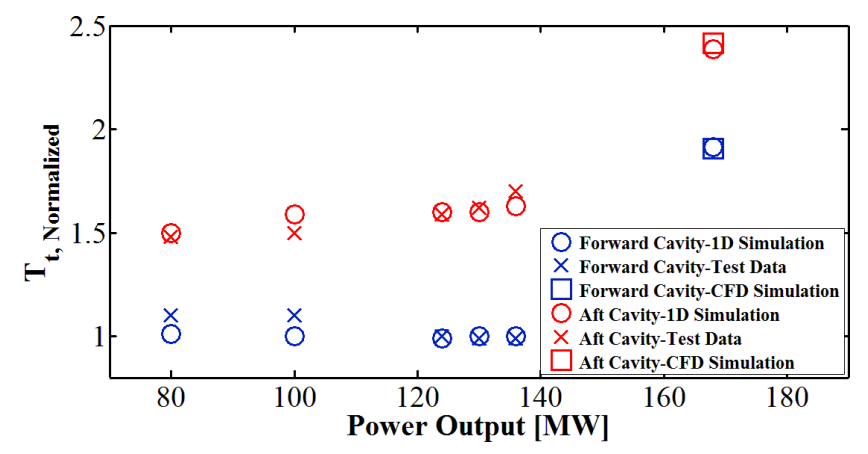

\section{Figure 21 Normalized flow temperature in stage 2 rim cavities}

As it can be seen in Fig. 21, the temperature predictions for aft cavity are better than forward cavity. The reason is that the uncertainty in amount and temperature of blade 1 root cooling flow is higher than other boundary conditions in 1D simulations. This leads to higher error for prediction of temperature in forward cavity compared to aft cavity.

\section{CONCLUSION}

Numerical and experimental investigations for a turbine stator-well sealing performance in MAPNA heavy-duty gas turbine MGT-70 is presented. Numerical investigations include 1D simulations using an in-house code and a highfidelity 3D simulation using CFD. Special attention is paid to sealing performance evaluation of both stator-well cavities. A new approach is proposed for to calculate sealing effectiveness in CFD simulations. The sealing performance is evaluated by classic and new-defined effectiveness definitions and compared with thermal condition of the components. The new definition is proved to be trusted and practical and more compliant with component thermal conditions. CFD results are also used for tuning the in-house 1D code.

The models are used during design iterations of turbine upgrade to assess the sealing performance in stator-rotor cavities and to insure that hot gas is not ingested into the cavities from the redesigned flow path. Test results from the first upgraded turbine shows a good agreement between simulation and measurement results and no ingestion is detected in rim cavities during different operating conditions.

\section{NOMENCLATURE}

c concentration of cooling air in a sample

CA cooling air

non-dimensional pressure asymmetry in

$\mathrm{C}_{\mathrm{p}, \mathrm{max}}$ circumference

CV control volume

$\mathrm{C}_{\mathrm{W}} \quad$ non-dimensional flow rate $\left[=\mathrm{m}^{*} / \mu \mathrm{R}\right]$

$\mathrm{C}_{\mathrm{w} \text {,min }}$ minimum value of $\mathrm{C}_{\mathrm{w}}$ to prevent ingress

$\mathrm{G}_{\mathrm{c}} \quad$ seal clearance ratio $[=\mathrm{s} / \mathrm{R}]$

HG hot gas

$\mathrm{K} \quad$ empirical constant

m mass

$\dot{\mathrm{m}} \quad$ mass flow rate

max maximum

q heat flux from cavity wall to cavity flow 
$\mathrm{R} \quad$ radius of seal

$\mathrm{Re}_{\mathrm{w}} \quad$ axial Reynolds number in annulus $[=\rho \mathrm{WR} / \mu]$

$\mathrm{s} \quad$ axial clearance between rotor and stator

$\mathrm{T}$ temperature

w axial velocity in annulus

$\Delta \theta \quad$ total angle of stationary sector

$\varepsilon \quad$ sealing effectiveness, surface-based definition

$\eta_{\mathrm{T}}$ sealing effectiveness, based on temperature measurements

$\eta_{\mathrm{c}} \quad$ sealing effectiveness, based on gas concentration measurements

$\theta \quad$ angular coordinate on stationary sector

$\mu \quad$ dynamic viscosity

$\rho$ density

\section{SUBSCRIPTS}

CA cooling air

e egress

HG hot gas

i ingress

o superimposed flow

ref reference

$1,2,3$ ingestion patterns

\section{ABBREVIATIONS}

CFD Computational fluid dynamics

CHT conjugate heat transfer

EI externally induced

HTC heat transfer coefficient

IGV inlet guide vane

SAS secondary air system

\section{ACKNOWLEDGMENTS}

This work was financially supported by MAPNA Group R\&D department.

\section{REFERENCES}

Bohn, D., Wolff, M. (2003). Improved Formulation to Determine Minimum Sealing Flow - Cw,min-for Different Sealing Configurations. ASME Paper no. GT2003-38465.

Clark, K., Barringer, M., Johnson, D., Thole, K. (2017). Effect of Purge Flow Configuration on Sealing Effectiveness in Rotor-Stator cavity. ASME Paper no. GT2017-63910.

Coren, D. D, Atkins, N. R., Turner, J. R., Eastwood, D. E., Davies, S., Childs, P. R. N., Dixon, J., Scanlon, T. S. (2010). An Advanced Multi-configuration Stator Well Cooling Test Facility. ASME Paper no. GT2010-23450.

Hills, N. J., Green, T., Turner, A. B. (1997). Aerodynamics of Turbine Rim-seal ingestion. ASME Paper no. 97-GT-268.

Jakoby, R., Zierer, T., Lindblad, K., Larsson, J., DeVito, L., Bohn, D. E., Funcke, J., Decker, A. (2004). Numerical Simulation of the Unsteady Flow Field in an Axial Gas Turbine Rim Seal Configuration. ASME Paper no. GT2004-53829.

Mirzamoghadam, A. V., Balasubramanian, J., Michael, M., Roy, R. P. (2017). Unsteady Pressure
Characteristics in the Mainstream/Disc cavity of a Turbine Stage. ASME Paper no. GT2017-63844.

Mirzamoghadam, A. V., Heitland, G., Morris, M. C., Smoke, J., Malak, M., Howe, J. (2008). 3D CFD Ingestion Evaluation of a High Pressure Turbine Rim Seal Disk cavity. ASME Paper no. GT2008-50531.

Mirzamoghadam, A. V., Molla-Hosseini, K., Gonzalez-Martino, I., Polidoro, F. (2017). Unsteady 360 Computational Fluid Dynamic Validation of a Turbine Stage Mainstream/Disc Cavity Flow Interaction Using Lattice-Boltzmann Method. ASME Paper no. GT201763841.

Palafox, P., Ding, Z., Bailey, J., Vanduser, T., Kirtley, K., Moore, K., Chupp, R. (2013). A New 1.5-Stage Turbine Wheel-space Hot Gas Ingestion Rig (HGIR) Part I: Experimental Test Vehicle, Measurement Capability and Baseline Results. ASME Paper no. GT2013-96020.

Phadke, U. P., Owen, J. M. (1983). An Investigation of Ingress for an Air-Cooled Shrouded Rotating Disk System With Radial-Clearance Seals. Journal of Engineering for Power, 105(1), pp. 178-182.

Phadke, U. P., Owen, J. M., 1983. "Aerodynamic Aspects of the Sealing of Gas Turbine Rotor-Stator Systems Part 3: The Effect of Non-axisymmetric External Flow on Seal Performance". International Journal of Heat and Fluid Flow, 9(2), pp. 113-117.

Poursamad, A., Motamedi Zoka, H., Shirzadi, M. R., Banihabib, R., Bahramitalab, A., Abedinnejad, Sh., Savadkouhi, P., Torabideh, R., Khanigouabad, A. (2019). Aero-thermal Upgrade of Turbine Section in MAPNA Heavy-Duty Gas Turbine MGT-70(3). Proceedings of GPPS 2019, GPPS-TC-2019-0057.

Reichert, A. W., Lieser, D. (1999). Efficiency of AirPurged Rotor-Stator Seals in Combustion Turbine Engines. ASME Paper no. 99-GT-250.

Sangan, C. M., Pountley, O. J., Zhou, K., Wilson, M., Owen, J. M., Lock, G. D. (2013). Experimental Measurements of Ingestion through Turbine Rim SealsPart I: Externally Induced Ingress. Journal Of Turbomachinery, 135(2), pp. 021012.

Sangan, C. M., Pountley, J. A., Scobie, K., Wilson, M., Owen, J. M., Lock, G. D. (2013). Experimental Measurements of Ingestion through Turbine Rim SealsPart III: Single and Double Seals. Journal Of Turbomachinery, 135(5), pp. 051011.

Scobie, J. A., Hualca, F. P., Patinios, M., Sangan, C. M., Owen, J. M., Lock, G. D. (2017). Re-ingestion of Upstream Egress in 1 1.5-Stage Gas Turbine Rig. ASME Paper no. GT2017-64620.

Wang, C. Z., Mathiyalagan, S. P., Johnson, B. V., Glahn, J. A., Cloud, D. F. (2014). Rim Seal Ingestion in a Turbine Stage from 360 Degree Time-Dependent Numerical Simulation. ASME Paper no. GT2012-68193. 